Indonesian Journal of Cardiology

Indonesian J Cardiol 2018:39:166-173

pISSN: 0I 26-3773 / elSSN: 2620-4762

doi: $10.30701 /$ ijc.v39i4.860

\title{
Relationship Between of Lactate Clearance with Major Cardiovascular Events in Patients with Acute Decompensated Heart Failure
}

\author{
David Ramli, 1 Masrul Syafri2, Muhammad Fadil,2 Ricvan Dana Nindrea3
}

I Faculty of Medicine, University of Andalas, West Sumatera, Indonesia;

2 Department of Cardiology and Vascular Medicine, M Djamil

Hospital, West Sumatera, Indonesia

3 Department of Public Health and Community Medicine Faculty of Medicine, University of Andalas, West Sumatera, Indonesia;

\section{Correspondence: David Ramli Faculty of Medicine, University of Andalas, West Sumatera, Indonesia E-mail: davidramli84@ gmail.com}

\begin{abstract}
Background: Acute decompensated heart failure (ADHF) still a major health problem with high morbidity and mortality. The risk stratification of ADHF patients is an important factor to determine the initial management. Examination of lactic acid levels is an inexpensive tool and mostly available at primary care centers. Lactate clearance, derivation of lactic acid level, is one of the modalities that can be used to assess risk stratification. The association between lactate clearance and in-hospital major cardiovascular events (MACE) of ADHF patients has not been studied yet.

Method: Observational approach with cross-sectional design. Data obtained from observations during treatment in ADHF patients at Dr. RSUP M. Djamil Padang in April-July 20 18. Bivariate analysis between variables lactate clearance and KKM was carried out during the treatment using the chi-square method and the Odds ratio was obtained.
\end{abstract}

Result: From 44 subjects, 22 of subjects experienced MACE. From the results were found significant differences in lactate clearance in both of groups, - I I,72 $\pm 4,25 \%$, vs $26,09 \pm 9,36 \%(p=<0,00 \mathrm{I})$. The association between lactate clearance and in-hospital major cardiovascular events of ADHF patients in this study obtained OR $\mathrm{I}, 16$ with $95 \% \mathrm{Cl} \mathrm{I}, 12-4,102(\mathrm{p}=0.000)$.

Conclusion: Lactate clearance is a valuable modality that can be used to make a risk stratification in ADHF patients.

(Indonesian J Cardiol. 2018;39:166-173)

Keywords: Lactate clearance, ADHF, risk stratification 


\title{
Hubungan Lactate Clearance dengan Kejadian Kardiovaskular Mayor pada Pasien Gagal Jantung Dekompensata Akut
}

\author{
David Ramli, 1 Masrul Syafri2, Muhammad Fadil,2 Ricvan Dana Nindrea 3
}

\begin{abstract}
Abstrak
Latar Belakang: Gagal jantung dekompensata akut (ADHF) masih merupakan masalah kesehatan dengan morbiditas dan mortalitas tinggi. Stratifikasi risiko pasien ADHF merupakan faktor penting untuk menentukan managemen awal. Pemeriksaan kadar asam laktat merupakan alat yang murah dan tersedia di pusat pelayanan primer, lactate clearance merupakan salah satu modalitas untuk menilai stratifikasi risiko. Hubungan antara lactate clearance dengan kejadian kardioavaskular mayor selama perawatan pada pasien ADHF belum diteliti.

Metode: Pendekatan observasional dengan desain potong lintang. Data diperoleh dari pengamatan selama perawatan pada pasien ADHF di RSUP Dr. M. Djamil Padang bulan April-Juli 2018. Dilakukan analisis bivariat antara varibel lactate clearance dengan KKM selama perawatan dengan menggunakan metode chi-square dan didapatkan nilai Odds ratio.

Hasil: Dari 44 subyek penelitian, 22 subjek dengan ADHF tidak mengalami KKM dan 22 subjek mengalami KKM. Hasil penelitian menemukan adanya perbedaan yang bermakna variabel lactate clerance pada kedua kelompok, yakni $-11,72 \pm 4,25$ $\%$ vs $26,09 \pm 9,36 \%$, dengan nilai $\mathrm{p}=<0,001$. Hubungan antara lactate clearance dengan kejadian kardioavaskular mayor selama perawatan pada pasien ADHF pada penelitian ini didapatkan nilai OR 1,16 dengan 95\% CI 1,12 - 4,102 (nilai $\mathrm{p}=<0,001$ ).

Kesimpulan: Lactate clearance dapat digunakan sebagai stratifikasi risiko pada pasien ADHF.
\end{abstract}

(Indonesian J Cardiol. 2018;39:166-173)

Kata kunci: Lactate clearance, ADHF, stratifikasi risiko

\footnotetext{
I Faculty of Medicine, University of Andalas, West Sumatera, Indonesia;

2 Department of Cardiology and Vascular Medicine, M Djamil Hospital, West Sumatera, Indonesia

3 Department of Public Health and Community Medicine Faculty of Medicine, University of Andalas, West Sumatera, Indonesia;

\section{Korespondensi:}

David Ramli

Faculty of Medicine, University of Andalas,

West Sumatera, Indonesia

E-mail: davidramli84@gmail.com
}

\section{Pendahuluan}

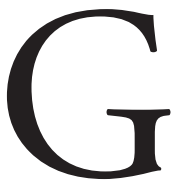
agal jantung akut merupakan penurunan fungsi pompa jantung yang terjadi secara tiba-tiba yang dapat mengancam nyawa sehingga membutuhkan penatalaksana segera. Ada 2 pembagian persentasi gagal jantung akut, yaitu gagal jantung akut yang baru pertama kali terjadi dan gagal jantung dekompensata akut yang terjadi karena adanya perburukan dari gagal jantung kronis yang sebelumnya telah stabil. ${ }^{(1,2)}$ 
Berdasarkan data dari WHO tahun 2014 prevalensi penderita gagal jantung akut di seluruh dunia sekitar 23 juta. Gagal jantung akut merupakan penyebab utama rawat inap pada orang tua dan menghabiskan anggaran dana yang cukup besar, sekitar $70 \%$ dari seluruh kasus gagal jantung. ${ }^{(4,10)}$ Angka mortalitas selama rawatan pasien dengan gagal jantung akut cukup tinggi berkisar antara $4 \%$ hingga $7 \%$, dimana angka mortalitas dalam 2 hingga 3 bulan setelah pulang rawatan meningkat menjadi $7 \%$ hingga 11\%.(3) Dikarenakan cukup tingginya angka mortalitas pasien dengan ADHF maka diperlukan adanya prediktor terhadap hasil luaran pasien rawatan dengan ADHF.Asam laktat merupakan senyawa kimia yang penting dalam metabolisme energi. (5,7) Pada kondisi ADHF dimana adanya curah jantung yang menurun akan menyebabkan tubuh memproduksi asam laktat. ${ }^{(8,9)}$

Lactate clearance merupakan index baru terhadap hasil luaran dan merupakan prediktor terhadap kematian pada pasien ADHF. Lactate clearance merupakan prediktor yang lebih baik karena memiliki rasio yang relative lebih stabil yang menggambarkan antara proses produksi dan eliminasi asam laktat. Penelitian terdahulu yang dilakukan oleh Scott pada tahun 2008 yang menemukan bahwa lactate clearance $>$ $15 \%$ yang diperiksa pada jam ke 2 pada pasien ADHF secara signifikan dapat memprediksi kelangsungan hidup. ${ }^{(6)}$ Dengan demikian dapat diambil kesimpulan bahwa lactate clearance yang diperiksa pada jam ke 2 dapat digunakan sebagai prediktor terhadap hasil luaran. Sehingga penelitian ini bertujuan untuk melihat kekuatan dari lactate clearance yang diperiksa pada jam ke 2 (lactate clearance 2 jam) dalam memprediksi terjadinya kejadian kardiovaskular mayor (KKM) selama rawatan pada pasien ADHF.

\section{Metode}

Penelitian ini menggunakan pendekatan observasional dengan desain studi potong lintang. Data diambil secara prospektif dari pengamatan terhadap pasien gagal jantung dekompensata akut yang dirawat di RSUP Dr. M. Djamil Padang bulan April-Juli 2018. Untuk kriteria inklusi adalah semua pasien rawatan dengan ADHF. Kriteria ekslusi adalah fraksi ejeksi $\geq 50 \%$, ketoasidosis diabetikum, hipoperfusi regional ( acute limb iskemia, sindrom kompartemen ), penyakit ginjal kronis ( LFG
< $60 \mathrm{ml} / \mathrm{mnt} / 1,73 \mathrm{~m} 2$ / albuminuria selama 3 bulan ), penyakit Hati ( sirosis dan hepatoma ), sepsis, anemia $(\mathrm{Hb}<7.5 \mathrm{~g} / \mathrm{dL})$, mengkonsumsi bahan yang dapat meningkatkan kadar asam laktat ( metformin, alkohol ), sindrom koroner akut. Data yang dikumpulkan adalah informasi demografi, hasil laboratorium, nilai fraksi ejeksi, kriteria forrester, obat-obatan yang digunakan, onset terjadinya KKM dan lama masa rawatan. Data demografis termasuk usia, jenis kelamin, faktor presipitasi, faktor resiko. Pemeriksaan kadar asam laktat dilakukan menggunakan alat Gem premiere dengan menggunakan metode ion selective electrode direct. Pengambilan sampel asam laktat dilakukan pada saat awal masuk di IGD sebelum mendapatkan terapi dan 2 jam kemudian setelah mendapat terapi. Kejadian kardiovaskular mayor ditentukan berdasarkan definisi 2014 ACC/AHA Key Data Elements and Definitions for Cardiovascular Endpoint Events in Clinical Trials yang diperoleh melalui iobservasi selama rawatan.

Lactate clearance diperoleh dari selisih antara kadar laktat 2 jam dengan kadar laktat awal dibagi dengan kadar laktat awal. Analisis statistik dilakukan untuk melihat hubungan antara variabel independen dan dependen digunakan uji chi-square dengan derajat kepercayaan 95\% dan $\alpha=0,05$. Apabila nilai $\mathrm{p}<0,05$ berarti terdapat hubungan yang bermakna antara statistik yang diteliti.

\section{Hasil}

Karakteristik pasien gagal jantung dekompensata akut dapat dilihat pada tabel 1. Dari total 58 pasien ADHF yang di rawat, 14 pasien dikeluarkan sesuai kriteria ekslusi sehingga didapatkan total 44 sampel, yaitu 22 pasien yang mengalami KKM dan 22 pasien yang tidak mengalami KKM. Pasien ADHF terbanyak berjenis kelamin laki-laki yang berjumlah 31 orang. Rerata umur responden pada kelompok yang mengalami KKM sedikit lebih tua yaitu 63,050 $\pm 11,416$, sedangkan pada kelompok tanpa KKM 57,950 $\pm 13,066$, tetapi tidak berbeda bermakna. Faktor resiko terbanyak adalah hipertensi diikuti dengan merokok, dislipidemia, diabetes mellitus, dan riwayat keluarga penyakit jantung koroner, dimana tidak terdapat perbedaan bermakna di antara kedua kelompok. Faktor presipitasi terbanyak adalah pneumonia, tidak mematuhi diet, tidak patuh minum obat dan aritmia, dimana tidak terdapat 
pebedaan bermakna antara kedua kelompok. Dari data laboratorium hemoglobin, leukosit, gula darah sewaktu, ureum, kreatinin, laju filtrasi glomerulus tidak terdapat perbedaan bermakna di antara kedua kelompok.

Kadar laktat awal tidak berbeda bermakna di antara kedua kelompok. Nilai laktat 2 jam pada kelompok yang mengalami KKM lebih tinggi dibandingkan dengan kelompok tanpa KKM yaitu 2,018 $\pm 0,465$ berbanding $1,527 \pm 0,462$. Kelompok KKM memiliki nilai lactate clearance yang lebih rendah dibandingkan tanpa KKM yaitu $-11,727 \pm 4,252$ berbanding 26,090 $\pm 9,358$. Dari hasil parameter ekokardiografi di dapatkan kelompok KKM memiliki nilai ejeksi fraksi yang lebih rendah yaitu 37,140 5 ,392 sedangkan kelompok tanpa KKM $44,050 \pm 4,520$. Berdasarkan kriteria forrester saat masuk semua pasien memiliki kriteria forrester kelas II. Dari data obat-obatan yang digunakan furosemide, nitrat, ace inhibitor, beta bloker dan MRA tidak terdapat perbedaaan bermakna di antara kedua kelompok. Dari data lama rawatan kelompok yang mengalami KKM memiliki masa rawatan yang lebih lama yaitu $8,000 \pm 2,410$ hari.

Data distribusi KKM dapat dilihat pada table 2. Jumlah KKM yang terbanyak adalah edem paru akut dan syok kardiogenik, diikuti dengan stroke, infark miokard akut (IMA) dan meninggal. Analisis hubungan antara lactate clearance dengan KKM selama perawatan dapat dilihat pada table 3. Dari analisis data didapat hubungan bermakna antara lactate clearance dengan KKM selama rawatan, dengan nilai $\mathrm{P}=<0,001$ dan nilai Odd ratio (OR) 1,16 (1,12-4,102).

\section{Diskusi}

Rerata umur responden pada kelompok yang mengalami KKM yaitu 63,050 $\pm 11,416$, sedangkan pada kelompok yang tidak KKM 57,950 $\pm 13,066$. Temuan ini sedikit berbeda dengan penelitian yang dilakukan oleh Scott (2009), yang menemukan rerata umur yang sedikit lebih tua, yaitu pada kelompok yang mengalami KKM $77.8 \pm 9.8$, sedangkan yang tidak KKM 75.5 \pm 9.2 . Pada penelitian ini lebih dari separoh responden berjenis kelamin laki-laki pada kedua kelompok, yaitu 68,2 $\%$ pada kelompok KKM dan 72,7 \% pada kelompok tanpa KKM. Temuan ini sedikit berbeda dengan penelitian yang dilakukan oleh Scott, yang menemukan lebih dari separoh responden berjenis kelamin laki-laki pada kelompok KKM yaitu $54 \%$, tetapi kurang dari separoh pada kelompok tanpa KKM yaitu $42 \% .6$ Perbedaan rerata umur subjek pada kedua penelitian dapat terjadi karena adanya perbedaan jumlah sampel yang digunakan pada masing-masing penelitian. ${ }^{(11,12)}$

Pada penelitian ini faktor risiko tidak berbeda bermakna antara kedua kelompok. Faktor risiko yang paling sering adalah hipertensi, diikuti oleh merokok, dislipidemia, diabetes mellitus dan yang terakhir riwayat penyakit keluarga. Temuan ini hampir sama dengan penelitian yang dilakukan Kawase pada tahun 2014 dimana mereka menemukan faktor risiko yang paling sering adalah hipertensi, diikuti dengan dislipidemia, diabetes mellitus dan riwayat penyakit keluarga. ${ }^{(5,13)}$

Faktor presipitasi terjadinya ADHF pada penelitian ini tidak berbeda bermakna antara kedua kelompok. Faktor presipitasi tersering adalah infeksi pneumonia diikuti tidak mematuhi diet, ketidakpatuhan minum obat dan adanya aritmia. Temuan ini hampir sama dengan penelitian yang dilakukan oleh Fischer pada tahun 2011. Dimana faktor presipitasi terbanyak adalah infeksi pneumonia diikuti aritmia, tidak mematuhi diet dan ketidak patuhan minum obat. Dari temuan ini diketahui bahwa adanya infeksi merupakan faktor presipasi yang paling sering menyebabkan terjadinya ADHF. Hal ini dapat terjadi karena pada pasienpasien ADHF cenderung mengalami penurunan sistim imunitas sehingga lebih retan untuk mengalami infeksi. $(2,14)$

Rerata kadar Hb pada kelompok KKM lebih rendah dibandingkan dengan kelompok tanpa KKM. Kadar Hb yang lebih rendah sering dikaitkan dengan morbiditas dan mortalitas yang lebih tinggi pada berbagai bidang kedokteran. Pasien dengan $\mathrm{Hb}$ yang lebih rendah cenderung memiliki tekanan darah yang lebih rendah dan frekuensi nadi yang lebih cepat. Hal ini dapat dijelaskan sebagai respon tubuh pada kondisi anemia. Kondisi anemia sendiri dapat memperberat terjadinya hipoperfusi jaringan yang akan meningkatkan produksi asam laktat. ${ }^{10}$

Pada penelitian yang dilakukan oleh Nguyen tahun 2009 pada pasien sepsis dan syok menemukan bahwa terdapat 2 mekanisme terjadinya peningkatan kadar asam laktat. Pada kondisi infeksi berat seperti sepsis peningkatan asam laktat terjadi karena adanya peningkatan metabolisme yang tinggi sedangkan pada kondisi syok terjadi karena adanya kondisi hipoperfusi jaringan. Pada pasien ADHF cenderung mengalami 
Indonesian Journal of Cardiology

Tabel 1. Karakteristik Dasar Subjek Penelitian

\begin{tabular}{|c|c|c|c|}
\hline Variabel & KKM & Tidak KKM & $\mathrm{p}$ value \\
\hline Umur dalam tahun (mean \pm SD) & $63,050 \pm 11,416$ & $57,950 \pm 13,066$ & 0,176 \\
\hline $\begin{array}{l}\text { Jenis kelamin, n (\%) } \\
\text { Laki-laki }\end{array}$ & $15(68,2)$ & $16(72,7)$ & 1,000 \\
\hline $\begin{array}{l}\text { Faktor risiko, n (\%) } \\
\text { Merokok } \\
\text { Hipertensi } \\
\text { Dislipidemia } \\
\text { Diabetes melitus } \\
\text { Riwayat keluarga PJK }\end{array}$ & $\begin{array}{l}10(45,5) \\
14(63,6) \\
8(36,4) \\
8(36,4) \\
2(9,1)\end{array}$ & $\begin{array}{c}12(54,5) \\
12(54,5) \\
7(31,8) \\
3(36,4) \\
0\end{array}$ & $\begin{array}{l}0,763 \\
0,759 \\
1,000 \\
1,000 \\
0,488\end{array}$ \\
\hline $\begin{array}{l}\text { Faktor presipitasi } \\
\text { Tidak patuh minum obat } \\
\text { Pneumonia } \\
\text { Tidak mematuhi diet } \\
\text { Aritmia }\end{array}$ & $\begin{array}{c}6(27,3) \\
15(68,2) \\
7(31,8) \\
1(4,5)\end{array}$ & $\begin{array}{c}5(22,7) \\
10(45,5) \\
5(22,7) \\
0\end{array}$ & $\begin{array}{l}1,000 \\
0,223 \\
0,735 \\
1,000\end{array}$ \\
\hline $\begin{array}{l}\text { Laboratorium saat admisi }(\text { mean } \pm \mathrm{SD}) \\
\text { Hemoglobin }(\mathrm{mg} / \mathrm{dl}) \\
\text { Leukosit }(\mathrm{mg} / \mathrm{dl}) \\
\text { Gula Darah Sewaktu }(\mathrm{mg} / \mathrm{dl}) \\
\text { Ureum }(\mathrm{mg} / \mathrm{dl}) \\
\text { Kreatinin }(\mathrm{mg} / \mathrm{dl}) \\
\text { eLFG } \\
\text { Laktat saat masuk IGD }(\mathrm{mmol} / \mathrm{dl}) \\
\text { Laktat setelah } 2 \text { jam }(\mathrm{mmol} / \mathrm{dl}) \\
\text { Nilai lactate clearance }(\%)\end{array}$ & $\begin{array}{c}12,591 \pm 1,563 \\
11342,636 \pm 3309,762 \\
155,682 \pm 64,509 \\
35,364 \pm 19,152 \\
1,355 \pm 0,263 \\
61,136 \pm 9,285 \\
1,936 \pm 0,571 \\
2,018 \pm 0,465 \\
-11,727 \pm 4,252\end{array}$ & $\begin{array}{c}13,091 \pm 1,849 \\
9452,727 \pm 3689,912 \\
166,500 \pm 80,258 \\
48,545 \pm 37,566 \\
1,186 \pm 0,341 \\
68,227 \pm 21,001 \\
2,155 \pm 0,406 \\
1,527 \pm 0,462 \\
26,090 \pm 9,358\end{array}$ & $\begin{array}{c}0,338 \\
0,081 \\
0,625 \\
0,153 \\
0,075 \\
0,155 \\
0,152 \\
0,001^{*} \\
<0,001^{*}\end{array}$ \\
\hline $\begin{array}{l}\text { Ekokardiografi } \\
\text { Fraksi ejeksi (\%) }\end{array}$ & $37,140 \pm 5,392$ & $44,050 \pm 4,520$ & $<0,001^{*}$ \\
\hline $\begin{array}{l}\text { Klasifikasi Forrester, n (\%) } \\
\text { Forester kelas } 1 \\
\text { Forester kelas } 2 \\
\text { Forester kelas } 3 \\
\text { Forester kelas } 4\end{array}$ & $\begin{array}{c}0 \\
22(100) \\
0 \\
0\end{array}$ & $\begin{array}{c}0 \\
22(100) \\
0 \\
0\end{array}$ & $\begin{array}{l}- \\
- \\
-\end{array}$ \\
\hline $\begin{array}{l}\text { Obat-obatan, n (\%) } \\
\text { Furosemid } \\
\text { Nitrat } \\
\text { Ace Inhibitor } \\
\text { Beta Blocker } \\
\text { MRA }\end{array}$ & $\begin{array}{l}22(100) \\
22(100) \\
22(100) \\
22(100) \\
9(40,9)\end{array}$ & $\begin{aligned} 22 & (100) \\
22 & (100) \\
22 & (100) \\
22 & (100) \\
2 & (9,1)\end{aligned}$ & $\begin{array}{c}- \\
- \\
- \\
- \\
0,037^{*}\end{array}$ \\
\hline $\begin{array}{l}\text { Lama rawatan dalam hari }(\text { mean } \pm S D) \\
\text { Onset KKM dalam hari }(\text { mean } \pm S D)\end{array}$ & $\begin{array}{l}8,000 \pm 2,410 \\
2,910 \pm 1,875\end{array}$ & $\begin{aligned} 5,320 & \pm 0,477 \\
& -\end{aligned}$ & $\begin{array}{c}<0,001^{*} \\
-\end{array}$ \\
\hline
\end{tabular}

Keterangan :

Signifikan pada $\mathrm{p}<0,05$

$\mathrm{LFG}=$ laju filtrasi glomerulus IGD = instalasi gawat darurat $\mathrm{PJK}=$ penyakit jantung koroner

penurunan sistim imunitas. Hal ini bisa terjadi selain karena faktor usia juga karena kurangnya aktifitas fisik akibat menurunnya kapasitas fungsional. $(3,15)$ Pada penelitian ini diketahui bahwa kelompok yang mengalami KKM lebih banyak menderita infeksi pneumonia dibandingkan dengan kelompok tanpa KKM. Begitu juga dengan kadar leukosit, kelompok dengan KKM cenderung memiliki nilai leukosit yang lebih tinggi jika dibandingkan dengan kelompok tanpa
KKM. Sehingga dapat disimpulkan bahwa kelompok yang mengalami KKM memiliki metabolisme yang lebih tinggi jika dibandingkan dengan kelompok tanpa KKM. Metabolisme yang tinggi cenderung membutuhkan konsumsi O2 yang lebih banyak. Apabila kebutuhan akan $\mathrm{O} 2$ ini tidak terpenuhi maka akan terjadi metabolisme secara anaerob yang akan meningkatan produksi asam laktat. ${ }^{(10,16)}$ 
Tabel 2. Distribusi Jenis KKM

\begin{tabular}{lcc}
\hline \multicolumn{1}{c}{ KKM } & $\mathrm{F}(22)$ & $\%$ \\
\hline Meninggal & 1 & 4,5 \\
IMA & 2 & 9,1 \\
Edema paru akut & 8 & 36,4 \\
Syok kardiogenik & 8 & 36,4 \\
Stroke & 3 & 13,6 \\
\hline
\end{tabular}

IMA= Infark miokard akut

Kadar asam laktat 2 jam setelah admisi pada kelompok yang mengalami KKM cenderung lebih tinggi dibandingkan dengan kelompok tanpa KKM dan berbeda secara statistik. Hal ini dikarenakan kelompok yang mengalami KKM memiliki lactate clearance yang lebih rendah dibandingkan dengan kelompok tanpa KKM. Hubungan antara lactate clearance dengan terjadinya KKM selama rawatan pasien ADHF pada penelitian ini didapatkan nilai OR 1,16 dengan $95 \%$ CI $(1,12-4,102)$ dengan nilai $\mathrm{p}=<0,001$. Temuan ini sejalan dengan penelitian sebelumnya yang dilakukan oleh Scott, yang menemukan bahwa lactate clearance dapat digunakan sebagai prediktor terhadap hasil luaran pasien rawatan dengan ADHF. Penelitian tersebut mendapatkan nilai OR 16,11 dengan 95 $\%$ CI $(6,53-39,7)$ dengan nilai $\mathrm{p}<<0,0011$. .6,17) $^{(6,10}$ Kelompok yang mengalami KKM memiliki lactate clearance yang cenderung lebih rendah jika dibanding dengan kelompok tanpa KKM yaitu $-11,727 \pm 4,252$ $\%$ vs $26,090 \pm 9,358 \%$ dan berbeda secara statistik dengan nilai $\mathrm{p}=<0,001$. Scott mendapatkan hasil lactate clearance yang sedikit berbeda, yaitu $-11 \pm 47 \%$ pada kelompok yang mengalami KKM dan $43 \pm 30 \%$ pada kelompok tanpa KKM dengan nilai $\mathrm{p}<0.05 .(6,18)$ Perbedaan nilai lactate clearance pada kedua penelitian ini dapat terjadi karena adanya perbedaan komorbid yang menyertai kondisi ADHF pada masing-masing penelitian.
Lactate clearance pada kondisi ADHF dipengaruhi oleh 2 mekanisme, yaitu kemampuan organ jantung dalam memompakan darah ke sirkulasi sistemik serta kemampuan organ hati dan ginjal dalam memetabolisme asam laktat. Penurunan curah jantung dapat menyebabkan terjadinya hipoperfusi jaringan yang akan meningkatkan produksi asam laktat, sedangkan gangguan fungsi hati dan ginjal akan menyebabkan menurunnya proses metabolisme asam laktat yang akan menyebabkan penumpukkan asam laktat pada sirkulasi sistemik. $^{(19,20)}$

Berdasarkan hasil pemeriksaan ekokardiografi didapatkan nilai fraksi ejeksi pada kelompok yang mengalami KKM lebih rendah dibandingkan dengan kelompok tanpa KKM yaitu 37,140 \pm 5,392 berbanding $44,050 \pm 4,520$ dan bermakna secara statistik dengan nilai $\mathrm{p}=<0,001$. Hal ini sejalan dengan hasil penelitian yang dilakukan Kawase dkk dimana pada kelompok yang mengalami KKM memiliki nilai fraksi ejeksi yang lebih rendah dibandingkan dengan kelompok tanpa KKM yaitu $50.1 \pm 13.9$ berbanding $50.8 \pm 13.8$ dengan nilai $\mathrm{p}<<0,0011 .(21,22)$ Perbedaan nilai fraksi ejeksi ini menunjukkan bahwa kelompok yang mengalami KKM cenderung mengalami penurunan kontraktilitas jantung yang lebih berat dibandingkan dengan kelompok tanpa KKM. Penurunan kontraktilitas akan menyebabkan terjadinya kegagalan jantung dalam memompakan darah ke sirkulasi sistemik untuk memenuhi kebutuhan $\mathrm{O} 2$ jaringan. Hal ini akan menyebabkan terjadinya kondisi hipoksia jaringan. Pada kondisi hipoksia jaringan akan terjadi peningkatan aktiftas enzim laktat dehidrogenase, dimana enzim ini akan mengkonversi asam piruvat menjadi asam laktat dan menghasilkan energi sebanyak 2 mol ATP.

Adanya penurunan kontraktilitas jantung juga akan menyebabkan terjadinya gangguan transfer asam laktat ke hati untuk dimetabolisme melaui proses glukoneogenesis guna menghasilkan glukosa. Hal ini

Tabel 3. Hubungan antara lactate clearance dengan KKM selama perawatan pada pasien ADHF

\begin{tabular}{|c|c|c|c|c|c|c|c|c|}
\hline \multirow{3}{*}{$\begin{array}{l}\text { Lactate } \\
\text { clearance }\end{array}$} & \multicolumn{4}{|c|}{ KKM } & \multirow{2}{*}{\multicolumn{2}{|c|}{ Jumlah }} & \multirow{3}{*}{$\begin{array}{c}\text { OR } \\
(95 \% \mathrm{CI})\end{array}$} & \multirow{3}{*}{ P-value } \\
\hline & \multicolumn{2}{|c|}{ KKM } & \multicolumn{2}{|c|}{ Tidak KKM } & & & & \\
\hline & $\mathrm{f}$ & $\%$ & $\mathrm{f}$ & $\%$ & $\mathrm{~F}$ & $\%$ & & \\
\hline$>15 \%$ & 3 & 13,6 & 20 & 90,9 & 23 & 52,3 & 1,16 & \\
\hline$<15 \%$ & 19 & 86,4 & 2 & 9,1 & 21 & 47,7 & $(1,12-4,102)$ & $<0,001$ \\
\hline Jumlah & 22 & 100 & 22 & 100 & 44 & 100 & & \\
\hline
\end{tabular}

$\mathrm{KKM}=$ Kejadian Kardiovaskular Mayor;OR=Odds ratio;CI=Confidence Interval 
akan menyebabkan terjadinya penumpukan asam laktat pada sirkulasi sistemik. Penurunan kontraktilitas jantung juga akan menyebabkan terjadinya stasis aliran darah di pembuluh paru yang akan meningkatkan resistensi pembuluh darah paru. Peningkatan resistensi pembuluh paru ini akan menyebabkan terjadinya perpindahan cairan dari pembuluh darah ke dalam alveoli sehingga terjadi bendungan di alveoli. Bendungan cairan ini akan menyebabkan terjadinya gangguan difusi $\mathrm{O} 2$ dari alveoli ke dalam pembuluh darah. Hal ini akan memperberat kondisi hipoksia jaringan yang akan meningkatkan produksi asam laktat. Selain itu penurunan kontraktilitas jantung juga akan menyebabkan terganggunya transfer obat ke hati untuk dimetabolisme, sehingga hal ini akan menghambat upaya farmakologis untuk mengatasi kondisi hipoksia jaringan. ${ }^{23,24)}$ Dengan demikian dapat disimpulkan bahwa rendahnya nilai fraksi ejeksi pada kelompok yang mengalami KKM dapat dijadikan sebagai etiologi yang mendasari penyebab rendahnya lactate clearance pada kelompok ini.

\section{Kesimpulan}

Pasien ADHF yang mengalami KKM memiliki usia relatif lebih tua dan terbanyak laki-laki, dengan faktor risiko yang paling banyak adalah hipertensi diikuti dengan merokok, dislipidemia, diabetes mellitus dan riwayat penyakit keluarga. Nilai rerata lactate clearance pada pasien ADHF yang mengalami KKM lebih rendah dibanding dengan kelompok tanpa KKM. Terdapat hubungan yang bermakna antara lactate clerance dengan kejadian kardiovaskular mayor selama perawatan pada pasien ADHF dengan nilai $\mathrm{p}=<0,001$ dan nilai $\mathrm{OR} 1,16$ $(1,12-4,102)$.

\section{Persetujuan Etik}

Penelitian ini adalah hasil karya sendiri, dan semua sumber yang ikutip maupun dirujuk telah dinyatakan dengan benar dan telah lolos kaji etik

\section{Persetujuan untuk Publikasi}

Semua pihak telah menyetujui publikasi penelitian ini.

\section{Konflik Kepentingan}

Tidak ada konflik kepentingan dalam pelaksanaan penelitian ini.

\section{Pendanaan}

Pendanaan penelitian ini berasal dari dana pribadi peneliti.

\section{Daftar Singkatan}

ADHF : Acute Decompensated Heart Failure

AKI : Acute Kidney Injury

ACC : American College of Cardiology

AHA : American Heart Association

ATP : Adenosin trifosfat

ADP : Adenosin difosfat

AUC : Area Under Curve

ADH : Anti Diuretic Hormone

CKD : Chronic Kidney disease

CI : Confidence Interval

DM : Diabetes Mellitus

ESC : European Society of Cardiology

EKG : Elektrokardiografi

FFA : Free Fatty Acid

HDL : High Density Lipoprotein

IMA : Infark Miokard Akut

IGD : Instalasi Gawat Darurat

IPJT : Instalasi Pelayanan Jantung Terpadu

JAMA : Journal of American Medical Association

KKM : Kejadian Kardiovaskular Mayor

LFG : Laju Filtrasi Glomerolus

LDL : Low Density Lipoprotein

LVEF : Left Ventricular Ejection Fraction

MAP : Mean Arterial Pressure

NO : Nitrous Oxide

NSTEMI : Non ST Elevation Myocardial Infarction

OR : Odds ratio

PCWP : Pulmonary Capillary Wedge Pressure

\section{Daftar Pustaka}

1. Ponikowski P, Voors AA, Anker SD, Bueno H, Cleland JGF, Coats AJS, et al. 2016 ESC Guidelines for the diagnosis and treatment of acute and chronic heart failure. Euro Heart Journal. 2016;37(27):2129-2200m. 
2. Ramani G V, Uber PA, Mehra MR. Chronic heart failure: Contemporary diagnosis and management. Mayo Clinic Proceedings. 2010;85(2):180-95.

3. O'Neal WT, Mazur M, Bertoni AG, Bluemke DA, Al-Mallah MH, Lima JAC, et al. Electrocardiographic predictors of heart failure with reduced versus preserved ejection fraction: The multi-ethnic study of atherosclerosis. J American Heart Association. 2017;6(6):1-9.

4. Bagaswoto HP, Dinarti LK, Maharani E. Scoring system based on electrocardiogram features to predict the type of heart failure in patients with chronic heart failure. Journal Medical Science. 2016;48(3):131-41.

5. Dahlan MS. Penelitian prognostik dan sistem skoring. Jatinangor: Penerbit Alqa Prisma Interdelta, 2011; p:49-125.

6. Roger VL. Epidemiology of heart failure. Circulation research. 2013; 113(6):646-649

7. Deswal A, Bockort S. Comparison of morbidity in women vs men with heart failure and preserved ejection fraction. American Journal of Cardiology. 2006; 97: 1228-1231

8. Azad N, Kathiravelu A, Minoosepeher S, Hebert P, Fergusson D. Gender differences in the etiology of heart failure: a systematic review. Journal of Geriatric Cardiology. 2011; 8: 15-23

9. Velagaleti RS, Gona P, Pencina MJ, Jayashri A, Wang TJ, Levy D, et al. Left ventricular hypertrophy patterns and incidence of heart failure with preserved versus reduced ejection fraction. American journal of cardiology. 2014; 113(1);1-16

10. Rickenbacher P, Kaufmann BA, Maeder MT, Bernheim A, Goetschalckx K, Pfiste O, et al. Heart failure with mid-range ejection fraction: a distinct clinical entity? Insights from the Trial of Intensified versus standard Medical therapy in Elderly patients with Congestive Heart Failure (TIME-CHF). European of Journal Heart Failure. 2017;19(12):158696.

11. Sandhu R, Bahler RC. Prevalence of QRS prolongation in a community hospital cohort of patients with heart failure and its relation to left ventricular systolic dysfunction. American Journal of Cardiology 2004;93:244 -246.

12. Murkofsky RL, Dangas G, Diamond JA, Mehta D, Schaffer A, Ambrose JA. A prolonged QRS duration on surface electrocardiogram is a specific indicator of left ventricular dysfunction. Journal of the American College of Cardiology. 1998;32:476 -482
13. Cincin A, Ozben B, Erdogan O. Diagnostic utility of specific electrocardiographical parameters in predicting left ventricular function. Experimental and Clinical Cardiology. 2012;17(4):210-4.

14. Kashani A, Barold SS. Significance of QRS complex duration in patients with heart failure. Journal of the American College of Cardiology. 2005;46(12):2183-92.

15. Kelly JP, Daubert JP. Prolonged QRS in Heart Failure With Preserved Ejection Fraction: Risk Marker and Therapeutic Target? JACC Heart Failure. 2016;4(6):487-9.

16. Dhingra R, Pencina MJ, Wang TJ, Nam B-H, Benjamin EJ, Levy D, et al. Electrocardiographic QRS Duration and the Risk of Congestive Heart Failure: The Framingham Heart Study. Hypertension. 2006;47(5):861-7.

17. Vrtovec B, Yazdanbakhsh AP, Pintar T, Collard CD, Gregoric ID, Radovancevic B. QTc interval prolongation predicts postoperative mortality. Texas Heart Institute Journal. 2006; 33: 3-8

18. Brendorp B, Elming H, Jun L, Kober L, Malik M, Jensen GB, et al. Qtc interval as a guide to select those patients with congestive heart failure and reduced left ventricular systolic function who will benefit from antiarrhythmic treatment with dofetilide. Circulation. 2001;103(10):1422-1427.

19. Lensen JMA, Fosse VN, Bovendeerd PHM, Strijkers GJ, Kuijpers NHL, Dam PM. Electrophysiology of the heart. From cardiac electrical activity to the ECG. 2008;5-7.

20. Karaye KM, Sani MU. Electrocardiographic abnormalities in patients with heart failure. Cardiovascular Journal of Africa. 2008;19(1):22-5.

21. Fang, Wai Lee AP, Man Yu C. Review: Left atrial function in heart failure with impaired and preserved ejection fraction. Current Opinion in Cardiology. 2014; 29:430-436

22. Basnet BK, Manandhar K, Shrestha R, Thapa M. Electrocardiograph and chest X-Ray in prediction of left ventricular systolic dysfunction. Journal of Nepal Medical Association. 2009;48(176):310-3.

23. Olesen LL, Andersen A. ECG as a first step in the detection of left ventricular systolic dysfunction in the elderly. ESC heart failure. 2016;3:44-52

24. Aro AL, Reiner K, Uy-Evanado A, Rusinaru C, Jui J, Chugh SS, et al. Prediction of moderate left ventricular systolic dysfunction from the 12-lead electrocardiogram. European Heart Journal. 2017;38 (Suppl 1):902 